Largo, to which he used to retire in the long vacation.

In person Sir John Leslie was of short stature and very corpulent, with protruding upper teeth, of florid complexion and rather deaf. In spite of these defects, it was a weakness of his in middle life to imagine himself both young and handsome. In keeping with this purely personal opinion, he dyed his hair. Unfriendly observers have related that, as his knowledge of chemistry was not so intimate as that of physics, the colour turned out to be purple. Sir John at times could deal with a very substantial meal, for it is recorded that in some sort of dietetic contest, he ate two pounds of almonds and raisins at the close of dinner. Another of Sir John's failings was distrust of the medical profession, so that he succumbed to the results of a neglected chill brought on by a severe wetting and complicated by erysipelas on November 3, 1832.

A caricature of Leslie is to be found in the wellknown "Kay's Portraits" ; and a copy of the bust by $\mathrm{S}$. Joseph has been placed in the National Portrait Gallery at Edinburgh.

\title{
Statistical Methods in Industry
}

$\mathrm{T}$ HE conception of the ordinary business man, whether in England or the United States, of the function of statistics in industry is generally a vague one. To many the word means no more than lists of figures open to various interpretations, while few have realised that the essential element lies not in the figures but in the science of their analysis. Marketing, costing, advertising, adjusting output to anticipate fluctuations in prices and demand, and recently studies in industrial psychology, have become recognised fields for the statistician. But the link between the methods of statistical analysis and the problems of the engineer, that is to say, of the man who is concerned with the efficiency of methods of production and the quality of the thing produced, has up to the present been very little realised.

Yet when dealing with mass-production industry, the scientific method of investigation is essentially the statistical method. For whether the manufacturer is concerned with the diameter of a shaft, the strength of cotton thread or the resistance of electrical equipment, he cannot succeed in producing exactly the same article again and again; and any attempt to analyse this variation in order to locate and if possible remove some of its causes, must be based on statistical technique.

Dr. W. A. Shewhart, of the Bell Telephone Laboratories, who visited London in May to give three lectures at University College on the "Rôle of Statistical Theory in Industrial Standardization", is chairman of a committee on the development of statistical applications in engineering and manufacturing, sponsored jointly by the American Society of Mechanical Engineers and the American Society for Testing Materials. He has been largely responsible for the development of this work in the United States, and his presence in England provided just the opportunity that was needed to bring together men in different fields who had begun to realise the importance of this work in England. An immediate development resulted when the British Standards Institution called to a round table conference representatives from several engineering groups, societies and research institutes. At this meeting a small committee was appointed under the chairmanship of $\mathrm{Mr}$. B. $\mathrm{H}$. Wilsdon, of the Department of Scientific and Industrial Research, Building Research Station, to investigate the whole problem from the point of view of standardisation and specification. This Committee is preparing a report which will include a pamphlet intended to serve as an introduction to the subject for manufacturers and others faced with these problems. Similar action, it is understood, has been taken in Germany by the Deutscher Normenausschuss.

It is true, of course, that for a number of years individual firms have here and there made use of statistical theory in laying out efficient research programmes to improve the quality of production, or to establish sampling plans to reduce the cost of inspection; but there has been little contact between those interested on these lines. The practical worker has not fully realised the potentiality of the statistical tool, nor has he had any opportunity of discovering how similar problems have been dealt with in the research institutes or factories of other firms in the same field or in other industries. At the same time, the mathematical statistician has not understood the lines along which theory could be developed most helpfully.

Recently in Great Britain Dr. Egon S. Pearson, of the Department of Applied Statistics at University College, London, has taken a leading part in an attempt to bring together those different interests. Dr. Pearson has not only made important contributions to the theory involved in this new field of practical statistics, but also has had the advantage of making a close study of its application to large-scale American engineering problems; while at the York Meeting of the British Association he contributed a paper on statistical methods in the quality-control of output, which attracted a considerable amount of attention.

The Biometric Laboratory at University College, with its position in London and its long tradition as a workshop of statistical tools, would appear to be admirably placed as a centre for the development of education and research in this particular field.

No. 3287, VoL. 130] 